\title{
Androgen receptor and FOXA1 coexpression define a "luminal-AR" subtype of feline mammary carcinomas, spontaneous models of breast cancer
}

Elie Dagher ${ }^{1}$, Violette Royer ${ }^{1}$, Paul Buchet ${ }^{1}$, Jérôme Abadie ${ }^{1,2}$, Delphine Loussouarn ${ }^{2,3}$, Mario Campone ${ }^{2,4}$ and Frédérique Nguyen ${ }^{1,24^{*}}$ (i)

\begin{abstract}
Background: Invasive mammary carcinomas that spontaneously develop in female cats are associated with high mortality, and resemble the most aggressive human breast cancers, especially triple-negative breast cancer (TNBC). Transcriptome studies showed that TNBCs are a heterogeneous group that includes a potentially hormonedependent subtype named luminal-AR. Some authors proposed an immunohistochemical definition of the luminalAR subtype, which is not only positive for Androgen Receptor (AR), but also either positive for the transcription factor Forkhead box A1 (FOXA1), or negative for basal markers. The objectives of this study were to describe AR and FOXA1 expressions in feline mammary carcinomas (FMCs), their prognostic value, and if their coexpression could define a "luminal-AR" subtype of triple-negative mammary carcinomas in cats.
\end{abstract}

Methods: In a previously described retrospective cohort of 180 female cats with FMCs, with a 2-year follow-up postmastectomy, we assessed AR, FOXA1, ER, PR, Ki-67, HER2, and CK14 expressions by automated immunohistochemistry.

Results: Of the 180 FMCs, 57 (32\%) were luminal; i.e., ER and/or PR positive, and 123 (68\%) were triple-negative (ER-, PR- and HER2-) FMCs. AR overexpression (found in 33 cases/180, 18\%) and FOXA1 index $\geq 1 \%(64 / 180,36 \%$ ) were associated with a longer disease-free interval, overall survival, and cancer-specific survival in cats with FMC. Analysis of AR, FOXA1 and CK14 coexpression in triple-negative FMCs showed that AR+ triple-negative FMCs were heterogeneous: there existed an AR+ FOXA1+CK14- subgroup $(n=7)$ associated with a better cancer-specific survival by multivariate survival analysis ( $\mathrm{HR}=0.26,95 \% \mathrm{Cl}: 0.07-0.89, p=0.03)$ compared to AR+ FOXA1-CK14+ triple-negative FMCs $(n=46)$ $(H R=1.00)$, independently of the pathologic tumor size and pathologic nodal stage. The non-basal-like subtype of triple-negative FMCs that coexpresses AR and FOXA1 (the AR+ FOXA1+CK14- subgroup) could represent the equivalent of the luminal-AR subgroup of human triple-negative breast cancer.

Conclusions: We identified an AR+ FOXA1+CK14- subgroup of triple-negative FMCs that might correspond to the luminal-AR subgroup of human triple-negative breast cancers. Cats with FMC may be interesting spontaneous animal models to investigate new strategies targeting the androgen receptor, especially in the aggressive subtype of AR+ basal-like triple-negative mammary carcinomas with loss of FOXA1 expression (the AR+ FOXA1-CK14+ subgroup).

Keywords: Androgen receptor, Feline mammary carcinoma, FOXA1, Luminal-AR breast cancer, Spontaneous animal model, Triple-negative breast cancer

\footnotetext{
* Correspondence: frederique.nguyen@oniris-nantes.fr

${ }^{1}$ AMaROC, Oniris (Nantes Atlantic College of Veterinary Medicine, Food

Science and Engineering), Oniris site Chantrerie, CS40706, 44307, Cedex 3,

Nantes, France

${ }^{2}$ CRCINA, INSERM, Université d'Angers, Université de Nantes, Nantes, France

Full list of author information is available at the end of the article
}

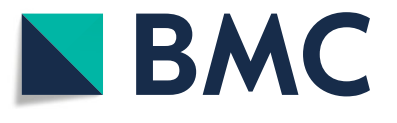

(c) The Author(s). 2019 Open Access This article is distributed under the terms of the Creative Commons Attribution 4.0 International License (http://creativecommons.org/licenses/by/4.0/), which permits unrestricted use, distribution, and reproduction in any medium, provided you give appropriate credit to the original author(s) and the source, provide a link to the Creative Commons license, and indicate if changes were made. The Creative Commons Public Domain Dedication waiver (http://creativecommons.org/publicdomain/zero/1.0/) applies to the data made available in this article, unless otherwise stated. 


\section{Background}

At least three factors justify that invasive mammary carcinomas that spontaneously arise in pet cats were proposed as relevant animal models for human breast cancer. The first is their high frequency: mammary tumors are reported to constitute $17 \%$ of neoplasms in female cats [1], are malignant in $80-90 \%$ of the cases [2,3], and most of these malignant tumors are carcinomas. The second is their aggressive biological behavior: the median overall survival time of cats with invasive mammary carcinomas is $8-12$ months post-diagnosis in most studies with follow-up [4-9]. The third is their resemblance with the most aggressive subtypes of breast cancer, for which targeted therapies are still needed: feline mammary carcinomas (FMCs) often lack significant levels of Estrogen Receptor (ER) and Progesterone Receptor (PR) expression, are rarely positive to HER2 (Human Epidermal growth factor Receptor 2), and thus most of them are considered to be triple-negative mammary carcinomas [10-19].

Transcriptome studies showed that triple-negative breast cancers (TNBCs) are a heterogeneous group. Among the major subtypes, the luminal-Androgen Receptor (luminal-AR) subtype appears to be a stable subgroup, characterized by high expression of downstream Androgen Receptor (AR) targets and coactivators [20]. Indeed, luminal-AR TNBC has been reported in multiple gene expression studies as reported by Lehmann et al. (2011 and 2016) [20, 21], Burstein et al. (2015) [22], and Jézéquel et al. (2015 and 2019) [23, 24]. Among others, luminal-AR breast cancers highly express the Forkhead box A1 (FOXA1) gene [20]. The transcription factor FOXA1 is able to bind to highly compacted chromatin, and acts as a pioneer factor with chromatin opening potential that allows other transcription factors and steroid hormone receptors to trigger transcriptional programs [25]. In the healthy mammary epithelial cell as well as in ER-positive breast cancers, FOXA1 is necessary for the expression of ER $\alpha$ target genes $[25,26]$. In addition, preclinical studies suggest that FOXA1 allows AR to bind to DNA and thereby induce transcription of AR target genes and stimulate tumor proliferation [27].

Since transcriptome studies are expensive, some authors proposed an immunohistochemical definition of the luminal-AR subtype of triple-negative breast cancer. Guiu et al. (2015) hypothesized that these two markers, AR and FOXA1, are needed to identify the luminal-AR TNBC subtype by immunohistochemistry [28]. Other authors such as Astvatsaturyan et al. (2018) defined the luminal-AR subtype of TNBC by its positivity for AR and negativity for Epidermal Growth Factor Receptor (EGFR), a basal marker [29].

As most of feline invasive mammary carcinomas are triple-negative $[11,13,19]$, the question arises of their heterogeneity. Here, we hypothesized that feline triple-negative mammary carcinomas may comprise, as in human TNBCs, a luminal-AR subtype, expected to be a non-basal-like TNBC with AR and FOXA1 coexpression, associated with a different biological behavior than other triplenegative FMCs.

The objectives of this study were thus 1) to investigate for the first time AR and FOXA1 expression in a large series of feline mammary carcinomas, 2) to assess their relationships with other clinical and pathological features of FMCs, 3) to investigate their prognostic significance in the feline patient, and 4) to put the first cornerstone for a better characterization of triple-negative FMCs, with identification of a luminal-AR subtype.

\section{Methods}

\section{Animals and inclusion criteria}

The present cohort of 180 female cats has been previously described [13]. Briefly, invasiveness of the included FMCs was confirmed by immunohistochemistry to a myoepithelial cell marker, p63 (clone 4A4, abcam ab111449), which can be used in both human [30, 31] and feline [32] mammary carcinomas. Feline patients benefited only from mastectomy. At diagnosis, clinical evaluation and medical imaging (radiography and/or ultrasonography) allowed excluding cases with another (non-mammary) malignancy, and to define the distant metastasis status: M0 (medical imaging revealed no distant metastasis), M1 (presence of distant metastases), or MX (no medical imaging performed). Follow-up was determined by veterinary evaluation for at least 48 months post-surgery. Prognosis was assessed in terms of disease-free interval (DFI), overall survival (OS), and cancer-specific survival (SS) [13]. This study was approved by the local ethical committee of our institution (CERVO, Comité d'Ethique en Recherche clinique et épidémiologique Vétérinaire d'Oniris, Nantes, France). Owner's written consent to participate was obtained prior to inclusion.

\section{Histologic methods and criteria}

Hematoxylin-Eosin-Saffron (HES)-stained sections of the FMCs were used to assess multicentricity, the histological type of feline mammary carcinoma, the pathologic tumor size $(\mathrm{pT})$ in millimeters, presence/absence of lymphovascular invasion (LVI), central necrosis, squamous differentiation, and tumor-associated lymphohistiocytic inflammation, as previously described [13, 33]. The histological grade was assessed using Elston and Ellis criteria for human breast cancer [34], which have been validated in cats [33]. The pathologic nodal stage was defined as pNO (negative pathologic nodal stage, on both an HES-stained section of the draining lymph node and an immunostained section for cytokeratins, clones AE1-AE3, Dako M3515), pN+ (positive pathologic nodal stage, for the presence of isolated tumor cells $(<0.2 \mathrm{~mm}$ in diameter), micro-metastases $(0.2-2.0 \mathrm{~mm}$ in 
diameter), or macrometastases $(>2.0 \mathrm{~mm})$ in the draining lymph node), or pNX (absence of lymph node sampled for histopathological examination). This allowed staging of the FMCs according to the modified World Health Organization (WHO) criteria [35, 36].

\section{Immunohistochemistry}

The immunohistochemical expression of Estrogen Receptor alpha (ER $\alpha)$, Progesterone Receptor (PR), Human Epidermal Growth Factor Receptor 2 (HER2), the proliferation marker Ki-67, Cytokeratin 14 (CK14), Androgen Receptor (AR), and Forkhead box A1 (FOXA1) were assessed using a Benchmark XT stainer (Ventana Medical Systems, Roche Diagnostics) (Table 1). Antibodies to ER, PR, HER2, Ki-67 and CK14 have been previously validated in cats [13, 37]. Antibodies to AR and FOXA1 were used here for the first time in cats. According to the NCBI-BLAST website (https://blast.ncbi.nlm.nih.gov/Blast.cgi), amino acid identity is $87 \%$ between human AR and feline AR proteins, and 89\% between human FOXA1 and feline FOXA1 proteins. Specificity of the anti-AR clone SP107 in cats was validated on normal feline tissues: AR immunoreactivity was found in the testis (interstitial Leydig cells, peritubular myoid cells), epididymis, uterus, ovary, hyperplastic mammary gland, cutaneous sebaceous glands, but absent in the gastrointestinal tract, liver, lung, heart, thyroid, parathyroid, hematopoietic and lymphoid tissues, skeletal muscle, adipose tissue, and nervous system, as expected in humans (https://www.proteinatlas.org). Similarly, the anti-FOXA1 clone SP88 cross-reacted with feline FOXA1, and was considered specific, as immunoreactivity was restricted to the hyperplastic mammary gland, cutaneous sweat glands, oviduct, bronchial epithelium, urinary bladder urothelium, and rare lymphocytes, as described in humans (https:// www.proteinatlas.org).

For negative controls, the primary antibodies were replaced by normal rabbit or mouse sera (prediluted reagents, Roche Diagnostics). Positive internal controls were the peritumoral mammary gland for $\mathrm{ER} \alpha, \mathrm{PR}, \mathrm{AR}$ and FOXA1, cutaneous sebaceous glands for ER $\alpha$ and AR, the epidermis and hair follicles for Ki-67 and CK14, and sweat glands for FOXA1. For HER2 IHC, the pathway HER2 4-in-1 control slides (Roche Diagnostics) were used as external positive controls.

A medical doctor specialist in breast cancer pathology (DL) and three certified veterinary pathologists (JA, FN, ED), blinded to the clinical outcome or clinicopathologic data, evaluated the immunostochemical data. ER $\alpha$ and PR were considered positive at a $10 \%$ threshold, as previously reported for dogs [38-40] and cats [13] with mammary carcinomas, and human breast cancers [41]. A threshold of $20 \%$ for the Ki-67 index was used to differentiate highly and poorly proliferative FMCs among hormone receptor-positive cases [42]. HER2 scores were assigned according to the recommendations for HER2 testing by IHC in breast cancers [43]. CK14 was considered positive when more than $15 \%$ of the tumor cells expressed the protein in their cytoplasm.

The 180 invasive feline mammary carcinomas were classified as luminal (ER+ and/or PR+, any HER2 score) or triple-negative $(\mathrm{ER} \alpha<10 \%, \mathrm{PR}<10 \%$, HER2 score 0 to 2+), including basal-like triple-negative carcinomas $(\mathrm{ER} \alpha<10 \%, \mathrm{PR}<10 \%, \mathrm{HER} 2$ score 0 to $2+, \mathrm{CK} 14 \geq$ $15 \%)$, as previously described $[10,13,18,19]$.

Nuclear AR expression was quantified as an index (percentage of positive neoplastic cells), and as an Allred score, whereas cytoplasmic AR immunoreactivity was

Table 1 Immunohistochemical protocols

\begin{tabular}{|c|c|c|c|c|c|}
\hline Antigen & $\begin{array}{l}\text { Clone and } \\
\text { origin }\end{array}$ & $\begin{array}{l}\text { Dilution, incubation } \\
\text { time }\end{array}$ & Source, reference & Antigen retrieval & Detection system \\
\hline ERa & $\begin{array}{l}\text { C311 mouse } \\
\text { mAb }\end{array}$ & $1: 5044 \mathrm{~min}$ & $\begin{array}{l}\text { Santa Cruz Biotechnology, } \\
\text { sc-787 }\end{array}$ & None & $\begin{array}{l}\text { iView DAB detection kit (Ventana Medical } \\
\text { Systems, Roche Diagnostics, 760-091) }\end{array}$ \\
\hline PR & $\begin{array}{l}10 A 9 \text { mouse } \\
\text { mAb }\end{array}$ & $1: 501 \mathrm{~h} 40 \mathrm{~min}$. & $\begin{array}{l}\text { Meridian Life Science, } \\
\text { K42546 M }\end{array}$ & $\mathrm{HIER}, \mathrm{CC} 1,1 \mathrm{~h}$ & iView DAB detection kit \\
\hline HER2 & 4B5 rabbit mAb & Prediluted 8 min & $\begin{array}{l}\text { Roche Diagnostics, 790- } \\
2991\end{array}$ & HIER, CC1, $30 \mathrm{~min}$ & $\begin{array}{l}\text { UltraView Universal DAB detection kit (Ventana } \\
\text { Medical Systems, Roche Diagnostics, 760-500) }\end{array}$ \\
\hline Ki-67 & $\begin{array}{l}\text { MIB1 mouse } \\
\text { mAb }\end{array}$ & $1: 5032 \mathrm{~min}$ & Dako, M7240 & HIER, CC $1,1 \mathrm{~h}$ & iView DAB detection kit \\
\hline $\begin{array}{l}\text { Cytokeratin } \\
14\end{array}$ & $\begin{array}{l}\text { LLO02 mouse } \\
\text { mAb }\end{array}$ & $1: 15044 \mathrm{~min}$ & $\begin{array}{l}\text { Santa Cruz Biotechnology, } \\
\text { sc-58,724 }\end{array}$ & HIER, CC1, 56 min & iView DAB detection kit \\
\hline$A R$ & $\begin{array}{l}\text { SP107 rabbit } \\
\text { mAb }\end{array}$ & 1:400 1 h 20 min. & Spring, M4070 & HIER, CC1, $30 \mathrm{~min}$ & $\begin{array}{l}\text { OptiView DAB IHC Detection Kit (Ventana Medical } \\
\text { Systems, Roche Diagnostics, 760-700) }\end{array}$ \\
\hline FOXA1 & $\begin{array}{l}\text { SP88 rabbit } \\
\text { mAb }\end{array}$ & $1: 501$ h $20 \mathrm{~min}$. & Spring, M3884 & HIER, CC1, 56 min & OptiView DAB IHC Detection Kit \\
\hline
\end{tabular}

CC1 Cell Conditioning solution 1, Ventana Medical Systems (reference 950-124) HIER Heat-induced epitope retrieval $m A b$ monoclonal antibody 
not considered in scoring. The Allred score is the sum of a proportion score, reflecting the percentage of ARpositive cells by immunohistochemistry (nuclear signal, on a scale of 0 to 5 points, respectively for $0, \leq 1 \%, 1-$ $10 \%, 11-33 \%, 34-66 \%$ and $\geq 67 \%$ of AR+ cells), and an intensity score (on a scale of 0 to 3 points, respectively for negative, weak, intermediate, and strong staining), for a possible total score of 8 points. AR overexpression was defined by Allred scores of 7-8 points, and AR positivity was defined as AR index $\geq 25 \%$. FOXA1 expression was quantified as the percentage of positive neoplastic cells (with nuclear signal) in at least 500 cancer cells (FOXA1 index in \%). The prognostic cutoffs (1\% for FOXA1, 25\% for AR positivity, Allred scores $7-8$ for AR overexpression) were determined by receiver-operatingcharacteristic curve analyses calculated for 2-year cancer-specific survival.

\section{Statistical analyses}

We have used the MedCalc ${ }^{\circ}$ statistical software (Ostend, Belgium) for all of the statistical analyses. Statistical associations between the clinicopathologic characteristics were evaluated using Chi-2 tests for categorical variables, one-way analysis of variance between a continuous and a categorical variable, and linear regression analysis among continuous variables. Univariate survival analyses were performed using the Kaplan-Meier method and log-rank tests, while multivariate survival analyses relied on Cox proportional hazards models. The results are expressed as the Hazard Ratio (HR), its 95\% confidence interval $(95 \% \mathrm{CI})$, and the $p$-value of each covariate. The significance threshold was set at $<0.05$.

\section{Results}

\section{Cohort description}

The main characteristics of the 180 female cats are reported in Table 2 . The mammary carcinoma was diagnosed at a mean age of $11.1 \pm 2.7$ years (range, 4.0-19.3 years). The cats were mainly European shorthair or longhaired cats $(154 / 180,86 \%)$, and Siamese (15/180, 8\%).

The pT (mean, $18 \pm 7 \mathrm{~mm}$; median, $18 \mathrm{~mm}$; range, $4-$ $48 \mathrm{~mm}$ ) was measurable in 150 cases, and imprecise in the 30 remaining cases, due to positive tumor margins. A hundred and one patients (56\%) had a positive pathologic nodal stage $(\mathrm{pN}+)$, and $8(4 \%)$ had distant metastases (M1) at diagnosis. The 180 FMCs were diagnosed at stage I in 45 cats $(25 \%)$, stage II in 23 cats (13\%), stage III in 104 cats (58\%) and stage IV in 8 cats $(4 \%)$.

Central necrosis was present in 160 cases (89\%), squamous differentiation in 81 cases (45\%), lymphovascular invasion (LVI) in 110 cases (61\%), and moderate to severe tumor-associated inflammation in 103 cases (57\%). According to the Elston and Ellis grading system, 10 cases (5\%) were grade I, $82(46 \%)$ were grade II and 88 (49\%) were grade III FMCs.

The mean ER $\alpha$ index was $10.0 \pm 13.3 \%$ (median, 5.4\%; range, $0-74.2 \%)$, with $88 \%$ of cases $(158 / 180)$ showing at least one ER+ neoplastic cell, but only 49 FMCs (27\%) were ER-positive. The mean PR index was $3.0 \pm 11.0 \%$ (median, 0\%; range, 0-87.8\%), most FMCs (144/180, $80 \%$ ) were totally devoid of PR expression, and only 13 (7\%) were PR-positive. None of the carcinomas overexpressed HER2 (3+ immunohistochemical score). The mean Ki-67 index was $45 \pm 14 \%$ (median, 45\%; range, 13-83\%). Fifty-seven FMCs (32\%) were luminal (ERand/or PR-positive, any HER2 score), including 8 luminal-A (Ki-67 index <20\%) and 49 luminal-B (Ki$67 \geq 20 \%)$ FMCs, and 123 (68\%) were triple-negative (ER-, PR-, HER2-).

At 15\% threshold for CK14 positivity, 132/180 (73\%) FMCs were CK14+, including 39 (68\%) of the 57 luminal FMCs and 93 (76\%) of the 123 triple-negative FMCs.

\section{AR expression in FMCs}

In the mammary gland surrounding FMCs, nuclear AR expression was usually intense but patchy, restricted to luminal cells in hyperplastic lobules and ducts; this level of expression corresponded to Allred scores ranging from 2 (weak staining in $\leq 1 \%$ of mammary epithelial cells) to 6 (strong AR expression in less than one-third of mammary epithelial cells). In FMCs, positive immunohistochemical staining for AR was most commonly nuclear, and was observed in neoplastic cells as well as scarce stromal cells including endothelial cells and cancer-associated fibroblasts (data not shown). Cytoplasmic AR immunoreactivity was observed in 82 FMCs (46\%), but was not taken into account for AR scoring. The mean percentage of ARpositive neoplastic cells (AR index) was $45 \pm 25 \%$ (median $45 \%$, range $0-95 \%)$. Most of the carcinomas (174/180, 97\%) contained at least one AR-positive neoplastic cell, whereas only few FMCs (6/180, 3\%) were completely devoid of AR expression. At 10\% threshold for AR positivity, $92 \%$ of the cases $(165 / 180)$ were positive for AR. When AR expression was quantified as an Allred Score, 33/180 (18\%) FMCs overexpressed AR (Allred scores 7-8 points), including 12/57 (21\%) luminal FMCs and 20/123 (16\%) triple-negative FMCs.

AR overexpression (Allred score $\geq 7$ ) was negatively correlated with (1) pathologic nodal stage $(\mathrm{OR}=0.32$, 95\% CI: $0.14-0.71, p<0.001)$ : only $33 \%(11 / 33)$ of FMCs with AR overexpression were $\mathrm{pN}+$ compared to $61 \%$ (90/147) of AR-negative FMCs; (2) lymphovascular invasion $(\mathrm{OR}=0.28,95 \% \mathrm{CI}: 0.13-0.62, p<0.01)$ : only $37 \%$ $(12 / 33)$ of FMCs with AR overexpression were LVI+ compared to 67\% (99/147) of AR-negative FMCs, and (3) clinical stage at diagnosis $(\mathrm{OR}=0.32,95 \%$ CI: 0.15 $0.70 \mathrm{p}<0.01)$ : only $41 \%(13 / 33)$ of FMCs with AR 
Table 2 Patients characteristics

\begin{tabular}{|c|c|c|c|}
\hline Parameters & Categories & $\mathrm{N}$ & $\%$ \\
\hline \multirow[t]{2}{*}{ Breed } & European shorthair or longhair & 154 & $85.6 \%$ \\
\hline & Other breeds & 26 & $14.4 \%$ \\
\hline \multirow[t]{2}{*}{ Gender } & Intact female & 112 & $62.2 \%$ \\
\hline & Neutered female & 68 & $37.8 \%$ \\
\hline \multirow[t]{3}{*}{ History of contraception } & Yes & 76 & $42.2 \%$ \\
\hline & No & 18 & $10.0 \%$ \\
\hline & Unknown & 86 & $47.8 \%$ \\
\hline \multirow[t]{2}{*}{ Previous benign mammary lesions } & Yes & 16 & $8.9 \%$ \\
\hline & No & 164 & $91.1 \%$ \\
\hline \multirow[t]{3}{*}{ Parity } & Nulliparous & 15 & $8.3 \%$ \\
\hline & Multiparous & 21 & $11.7 \%$ \\
\hline & Unknown & 144 & $80.0 \%$ \\
\hline \multirow[t]{2}{*}{ Multicentricity } & Multiple FMCs & 26 & $14.4 \%$ \\
\hline & Single FMC & 154 & $85.6 \%$ \\
\hline \multirow[t]{2}{*}{ Pathologic tumor size } & $\mathrm{pT}<20 \mathrm{~mm}$ & 85 & $47.2 \%$ \\
\hline & $\mathrm{pT} \geq 20 \mathrm{~mm}$ & 95 & $52.8 \%$ \\
\hline \multirow[t]{3}{*}{ Pathologic nodal stage } & pN+ (nodal metastasis) & 101 & $56.1 \%$ \\
\hline & pNo (no) & 20 & $11.1 \%$ \\
\hline & pNX (unknown) & 59 & $32.8 \%$ \\
\hline \multirow[t]{3}{*}{ Distant metastasis } & M1 (yes) & 8 & $4.4 \%$ \\
\hline & Mo (no) & 64 & $35.6 \%$ \\
\hline & MX (unknown) & 108 & $60.0 \%$ \\
\hline \multirow[t]{4}{*}{ WHO stage } & Stage I & 45 & $25.0 \%$ \\
\hline & Stage II & 23 & $12.8 \%$ \\
\hline & Stage III & 104 & $57.8 \%$ \\
\hline & Stage IV & 8 & $4.4 \%$ \\
\hline \multirow[t]{9}{*}{ WHO Histological type } & Cribriform & 54 & $30.0 \%$ \\
\hline & Comedocarcinoma & 50 & $27.8 \%$ \\
\hline & Solid & 27 & $15.0 \%$ \\
\hline & Mucinous & 15 & $8.3 \%$ \\
\hline & Tubulopapillary & 12 & $6.7 \%$ \\
\hline & Tubular & 9 & $5.0 \%$ \\
\hline & Papillary & 7 & $3.9 \%$ \\
\hline & Adenosquamous & 4 & $2.2 \%$ \\
\hline & Anaplastic & 2 & $1.1 \%$ \\
\hline \multirow[t]{3}{*}{ Elston and Ellis histological grade } & Grade I & 10 & $5.5 \%$ \\
\hline & Grade ॥ & 82 & $45.6 \%$ \\
\hline & Grade III & 88 & $48.9 \%$ \\
\hline \multirow[t]{2}{*}{ Lymphovascular invasion } & LVI+ & 110 & $61.1 \%$ \\
\hline & LVI- & 70 & $38.9 \%$ \\
\hline \multirow[t]{2}{*}{ Tumor-associated inflammation } & Absent to mild & 77 & $42.8 \%$ \\
\hline & Moderate to severe & 103 & $57.2 \%$ \\
\hline \multirow[t]{2}{*}{ Estrogen Receptor (ERa) } & $E R+(E R \geq 10 \%)$ & 49 & $27.2 \%$ \\
\hline & ER- $(E R<10 \%)$ & 131 & $72.8 \%$ \\
\hline
\end{tabular}


Table 2 Patients characteristics (Continued)

\begin{tabular}{|c|c|c|c|}
\hline Parameters & Categories & $\mathrm{N}$ & $\%$ \\
\hline \multirow[t]{2}{*}{ Progesterone Receptor (PR) } & $P R+(P R \geq 10 \%)$ & 13 & $7.2 \%$ \\
\hline & PR- $(P R<10 \%)$ & 167 & $92.8 \%$ \\
\hline \multirow[t]{4}{*}{ HER2 Score } & 0 & 103 & $57.2 \%$ \\
\hline & $1+$ & 59 & $32.8 \%$ \\
\hline & $2+$ & 18 & $10.0 \%$ \\
\hline & $3+$ & 0 & 0 \\
\hline \multirow[t]{2}{*}{ Ki-67 } & High Ki-67 ( $\geq 20 \%)$ & 169 & $93.9 \%$ \\
\hline & Low Ki-67 (< 20\%) & 11 & $6.1 \%$ \\
\hline \multirow[t]{2}{*}{ CK14 } & CK14+ ( $\geq 15 \%)$ & 132 & $73.3 \%$ \\
\hline & CK14- $(<15 \%)$ & 48 & $26.7 \%$ \\
\hline
\end{tabular}

overexpression were diagnosed at stage III or IV compared to $67 \%(99 / 147)$ of AR-negative FMCs. In addition, the AR index was negatively associated with (4) the pathologic tumor size $\left(\mathrm{R}^{2}=0.026\right.$ and $\left.p=0.048\right)$, (5) the Elston and Ellis histological grade $(p=0.002)$ : grade I and II FMCs had an AR index of $51 \pm 24 \%$ compared to $39 \pm 24 \%$ for grade III carcinomas, and (6) tumorassociated inflammation $(p=0.016)$ : FMCs with moderate to severe tumor-associated inflammation had an AR index of $41 \pm 25 \%$, compared to $50 \pm 25 \%$ in FMCs with absent to mild tumor-associated inflammation.

In triple-negative FMCs, AR overexpression was negatively correlated with (1) the Elston and Ellis histological grade $(\mathrm{OR}=0.25,95 \% \mathrm{CI}$ : $0.08-0.80, p=0.020)$ : only $20 \%$ $(4 / 20)$ of AR-overexpressing triple-negative FMCs were grade III compared to $50 \%$ (51/103) of AR-negative triplenegative FMCs, and (2) lymphovascular invasion $(\mathrm{OR}=$ 0.33, 95\% CI: $0.12-0.88, p=0.040)$ : only $40 \%(8 / 20)$ of ARoverexpressing triple-negative FMCs were $\mathrm{LVI}+$ compared to $67 \%(69 / 103)$ of AR-negative triple-negative FMCs.

\section{FOXA1 expression in FMCs}

Positive immunohistochemical staining to FOXA1 was also nuclear, and was observed in neoplastic cells as well as scarce tumor-infiltrating lymphocytes (data not shown). In the $180 \mathrm{FMCs}$, the mean FOXA1 index was $3.8 \pm 9.9 \%$ (median 0, range 0-85.1\%). Seventy-eight (43\%) of the carcinomas contained at least one FOXA1-positive neoplastic cell whereas the other 102 (57\%) were completely devoid of FOXA1 expression. At a FOXA1 index $\geq 1 \%, 64 / 180$ (36\%) FMCs were FOXA1+, including 28/57 (49\%) luminal FMCs and 36/123 (29\%) triple-negative FMCs.

FOXA1 index $\geq 1 \%$ was negatively correlated with the (1) pathologic nodal stage (OR $=0.46,95 \% \mathrm{CI}$ : $0.25-0.46$, $p=0.020)$ : only $44 \%(28 / 64)$ of FOXA1-positive FMCs were $\mathrm{pN}+$ compared to 63\% (73/116) of FOXA1negative FMCs, (2) Elston and Ellis histological grade $(\mathrm{OR}=0.14,95 \%$ CI: $0.03-0.70, p=0.010): 89 \%$ (57/64) of
FOXA1-positive FMCs were grade II or III compared to 98\% (114/116) of FOXA1-negative FMCs, (3) clinical stage at diagnosis $(\mathrm{OR}=0.37,95 \% \mathrm{CI}: 0.20-0.70, p=$ 0.003): $47 \%$ (30/64) of FOXA1-positive FMCs were stage III or IV compared to $71 \%(82 / 116)$ of FOXA1-negative FMCs, (4) lymphovascular invasion $(\mathrm{OR}=0.34,95 \% \mathrm{CI}$ : $0.18-0.64, p<0.001)$ : only $44 \%(28 / 64)$ of FOXA1positive FMCs were LVI+ compared to $70 \%(81 / 116)$ of FOXA1 negative FMCs, and (5) the Ki-67 proliferation index $(\mathrm{OR}=0.51,95 \% \mathrm{CI}: 0.27-0.95, p=0.040)$ : $50 \%$ (32/64) of FOXA1-positive FMCs had a high proliferation index $(\geq 42 \%)$ compared to $66 \%(77 / 116)$ of FOXA1-negative FMCs. FOXA1 index $\geq 1 \%$ was positively correlated to (6) $\mathrm{PR}$ positivity (OR $=7.74,95 \% \mathrm{CI}$ : 3.42-17.51, $p<0.0001): 42 \%$ (27/64) of FOXA1-positive FMCs were $\mathrm{PR}+$ compared to only $9 \%$ (10/116) of FOXA1-negative FMCs, (7) AR $(p=0.032)$ : FOXA1positive FMCs had an AR index of $50 \pm 25 \%$ compared to $42 \pm 25 \%$ in FOXA1-negative FMCs, and finally FOXA1 was positively correlated with (8) the luminal phenotype $(\mathrm{OR}=2.33,95 \% \mathrm{CI}: 1.22-4.46, p=0.010)$ : $44 \%(28 / 64)$ of FOXA1 positive FMCs were luminal compared to 25\% (29/116) of FOXA1 negative FMCs.

In triple-negative FMCs, FOXA1 index $\geq 1 \%$ was negatively correlated with (1) lymphovascular invasion (OR = 0.40 , $95 \%$ CI: $0.18-0.89, p=0.040)$ : only $47 \%(17 / 36)$ of FOXA1-positive triple-negative FMCs were $\mathrm{LVI}+$, compared to $69 \%(60 / 87)$ of FOXA1-negative triple-negative FMCs. The FOXA1 index of was also negatively correlated to (2) clinical stage $(p=0.026)$ : stage I-II triple-negative FMCs had a FOXA1 index of $2.7 \pm 6.2 \%$ compared to only $0.9 \pm 2.4 \%$ for stage III-IV triple-negative carcinomas, (3) pathologic nodal stage $(p=0.049)$ : the $70 \mathrm{pN}+$ triplenegative FMCs had a FOXA1 index of only $0.9 \pm 2.6 \%$, compared to $2.5 \pm 5.7 \%$ in the $53 \mathrm{pN0}$-pNX triple-negative carcinomas, (4) Elston and Ellis histological grade ( $p=$ 0.046): grade I-II triple-negative FMCs had a FOXA1 index of $2.3 \pm 5.3 \%$, compared to only $0.7 \pm 2.0 \%$ for grade 


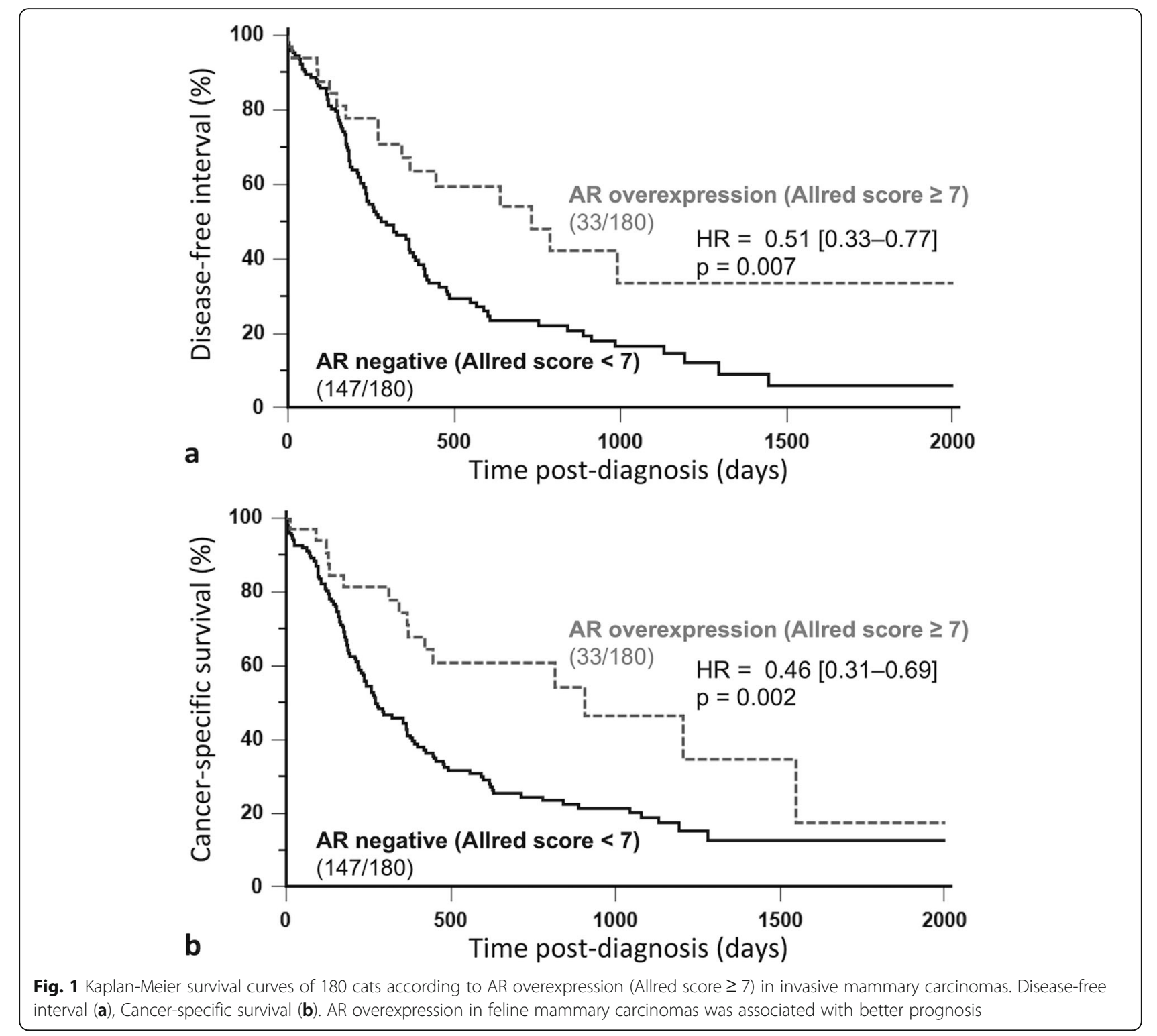

III triple-negative carcinomas, and finally FOXA1 expression was also positively correlated with (5) the AR index $\left(\mathrm{R}^{2}=0.044\right.$ and $\left.p=0.019\right)$.

\section{Prognostic value of AR and FOXA1 in FMCs}

AR overexpression (Allred score $\geq 7$ ) was associated with longer disease-free interval ( $\mathrm{HR}=0.51,95 \% \mathrm{CI}$ : $0.33-$ $0.77, p=0.007$; Fig. 1a) by univariate survival analysis. The other clinicopathologic factors significantly associated with disease-free interval were the pathologic tumor size ( $\mathrm{pT} \geq 20 \mathrm{~mm}$ versus $<20 \mathrm{~mm}: p=0.025, \mathrm{HR}=1.51$ ), pathologic nodal stage ( $\mathrm{pN}+$ versus $\mathrm{pN} 0-\mathrm{pNX}: p=$ $0.015, \mathrm{HR}=1.56$ ), distant metastasis ( $\mathrm{M} 1$ versus $\mathrm{M} 0$ MX: $p<0.0001, H R=5.35$ ), lymphovascular invasion (LVI+ versus LVI-: $p=0.0002, \mathrm{HR}=1.97$ ), and PR positivity ( $\mathrm{PR} \geq 10 \%$ versus $\mathrm{PR}<10 \%: p=0.043, \mathrm{HR}=0.48$ ).
By multivariate survival analysis, AR overexpression was associated with longer disease-free interval, independently of the pathologic tumor size and distant metastasis (Table 3).

AR overexpression (Allred score $\geq 7$ ) was also associated with longer overall survival $(\mathrm{HR}=0.60,95 \% \mathrm{CI}$ $0.42-0.85, p=0.011$ ) by univariate survival analysis, and the other clinicopathologic parameters associated with overall survival were patient age at diagnosis $(p=0.035$, $\mathrm{HR}=0.72$ if $\leq 11$ years), the pathologic tumor size ( $p=$ $0.0007, \mathrm{HR}=1.68$ if $\mathrm{pT} \geq 20 \mathrm{~mm}$ ), pathologic nodal stage $(p=0.0001, \mathrm{HR}=1.78$ if $\mathrm{pN}+)$, distant metastasis $(p=$ $0.002, \mathrm{HR}=2.89$ if $\mathrm{M} 1)$, lymphovascular invasion $(p<$ $0.0001, \mathrm{HR}=2.33$ if LVI+), histological grade $(p=0.023$, $\mathrm{HR}=1.41$ if grade III), cutaneous ulceration ( $p=0.025$, $\mathrm{HR}=1.51$ if present), tumor-associated inflammation 
Table 3 Prognostic value of AR overexpression in FMCs estimated by multivariate analysis (180 cases)

\begin{tabular}{|c|c|c|c|c|}
\hline & Categories & $\mathrm{p}$ & $\mathrm{HR}$ & $95 \% \mathrm{Cl}$ \\
\hline \multicolumn{5}{|l|}{ Disease-free interval } \\
\hline AR overexpression & AR+ (Allred Score $\geq 7$ ) vs. AR- & 0.023 & 0.54 & $0.31-0.91$ \\
\hline Pathologic tumor size & $\mathrm{pT} \geq 20 \mathrm{~mm}$ versus $<20 \mathrm{~mm}$ & 0.049 & 1.46 & $1.00-2.12$ \\
\hline Distant metastasis & $M 1$ versus $M 0-M X$ & $<0.0001$ & 4.87 & $2.32-10.23$ \\
\hline \multicolumn{5}{|l|}{ Overall survival } \\
\hline AR overexpression & AR+ (Allred Score $\geq 7$ ) vs. AR- & 0.027 & 0.62 & $0.41-0.94$ \\
\hline Pathologic tumor size & $\mathrm{pT} \geq 20 \mathrm{~mm}$ versus $<20 \mathrm{~mm}$ & 0.001 & 1.68 & $1.23-2.29$ \\
\hline Distant metastasis & $\mathrm{M} 1$ versus $\mathrm{M0}-\mathrm{MX}$ & 0.007 & 2.72 & $1.32-5.64$ \\
\hline \multicolumn{5}{|l|}{ Cancer-specific survival } \\
\hline AR overexpression & AR+ (Allred Score $\geq 7$ ) vs. AR- & 0.024 & 0.54 & $0.32-0.92$ \\
\hline Pathologic tumor size & $\mathrm{pT} \geq 20 \mathrm{~mm}$ versus $<20 \mathrm{~mm}$ & 0.004 & 1.69 & $1.18-2.42$ \\
\hline Pathologic nodal stage & $\mathrm{pN}+$ versus pN0-pNX & 0.001 & 1.84 & $1.27-2.67$ \\
\hline Distant metastasis & M1 versus M0-MX & 0.002 & 3.23 & $1.55-6.76$ \\
\hline
\end{tabular}

( $p=0.0053, \mathrm{HR}=1.54$ if moderate to severe), and PR positivity $(p=0.021, \mathrm{HR}=0.49$ if $\mathrm{PR} \geq 10 \%)$. By multivariate survival analysis, AR overexpression was associated with longer overall survival, independently of the pathologic tumor size and distant metastasis (Table 3).

Finally, AR overexpression (Allred score $\geq 7$ ) was associated with longer cancer-specific survival $(\mathrm{HR}=0.46,95 \%$ CI: $0.31-0.69, p=0.002$, Fig. 1 b) by univariate survival analysis. The other clinicopathologic factors associated with cancer-specific survival were the pathologic tumor size $(p=0.0006, \mathrm{HR}=1.82$ if $\mathrm{pT} \geq 20 \mathrm{~mm})$, pathologic nodal stage $(p=0.0001, \mathrm{HR}=2.03$ if $\mathrm{pN}+)$, distant metastasis $(p=0.0003, \mathrm{HR}=3.40$ if $\mathrm{M} 1)$, lymphovascular invasion $(p<0.0001, \mathrm{HR}=2.86$ if $\mathrm{LVI}+)$, tumor-associated inflammation ( $p=0.010, \mathrm{HR}=1.59$ if moderate to severe), and $\mathrm{PR}$ positivity $(\mathrm{p}=0.002, \mathrm{HR}=0.25$ if $\mathrm{PR} \geq 10 \%)$. The favorable prognostic value of AR overexpression in terms of cancer-specific survival was confirmed by multivariate analysis independently of the pathologic tumor size, pathologic nodal stage and distant metastasis (Table 3).

In luminal FMCs as well, AR overexpression was associated with favorable outcome in terms of cancer-specific survival $(\mathrm{HR}=0.38,95 \% \mathrm{CI}: 0.19-0.74 ; p=0.017)$ and overall survival ( $\mathrm{HR}=0.46,95 \% \mathrm{CI}$ : $0.25-0.82, p=0.024)$. In triple-negative FMCs also, AR overexpression was associated with longer disease-free interval $(\mathrm{HR}=0.49,95 \%$ CI: $0.28-0.85 ; p=0.037$ ) and cancer-specific survival $(\mathrm{HR}=0.53$, 95\% CI: 0.32-0.89; $p=0.046)$.

In the 180 FMCs studied, FOXA1 index $\geq 1 \%$ was associated with longer disease-free interval $(\mathrm{HR}=0.60,95 \% \mathrm{CI}$ : $0.41-0.87, p=0.008$; Fig. $2 \mathrm{a}$ ), longer overall survival ( $\mathrm{HR}=$ 0.73 , 95\% CI: $0.53-0.99, p=0.049)$, and longer cancerspecific survival $(\mathrm{HR}=0.60,95 \% \mathrm{CI}: 0.42-0.85 ; p=0.007$;
Fig. 2b) by univariate survival analysis. FOXA1 positivity (index $\geq 1 \%$ ) was also associated with favorable outcome in luminal FMCs, in terms of disease-free interval $(\mathrm{HR}=$ $0.39,95 \%$ CI: $0.21-0.75 ; p=0.002$ ) and cancer-specific survival (HR $=0.46,95 \%$-CI: $0.24-0.87 ; p=0.014)$. However, FOXA1 index $\geq 1 \%$ was not significantly associated with outcome in triple-negative carcinomas.

By multivariate survival analysis, FOXA1 index $\geq 1 \%$ was associated with longer disease-free interval and overall survival independently of the pathologic tumor size and distant metastasis (Table 4). The favorable prognostic value of FOXA1 index $\geq 1 \%$ was also observed in cancer-specific survival independently of the pathologic tumor size, pathologic nodal stage and distant metastasis (Table 4).

\section{Diversity of AR-positive triple-negative FMCs}

Of the 123 triple-negative FMCs, 53 (43\%) were ARpositive (AR index $\geq 25 \%$ ). Among AR-positive triplenegative FMCs, we identified two subgroups, a nonbasal-like subgroup (Fig. 3 a-f; $N=7$ ) characterized by double positivity to AR and FOXA1 (AR+FOXA1+ CK14-), defined by AR positivity (AR index $\geq 25 \%$ ), FOXA1 positivity (index $\geq 1 \%$ ) and CK14 negativity (CK14< 15\%), and a basal-like subgroup (Fig. 3 g-l; $N=46$ ) with loss of FOXA1 expression (AR+ FOXA1- CK14+). Both subgroups did not significantly differ by tumor stage, nodal status, stage at diagnosis, or histological grade (data not shown). However, the non basal-like AR+ FOXA1+ CK14- subgroup was associated with longer disease-free interval $(p=0.011$, Fig. 4a) and longer cancer-specific survival (HR $=0.33,95 \% \mathrm{CI}$ : 0.15 $0.70, p=0.043$; Fig. 4 b) by univariate survival analysis 


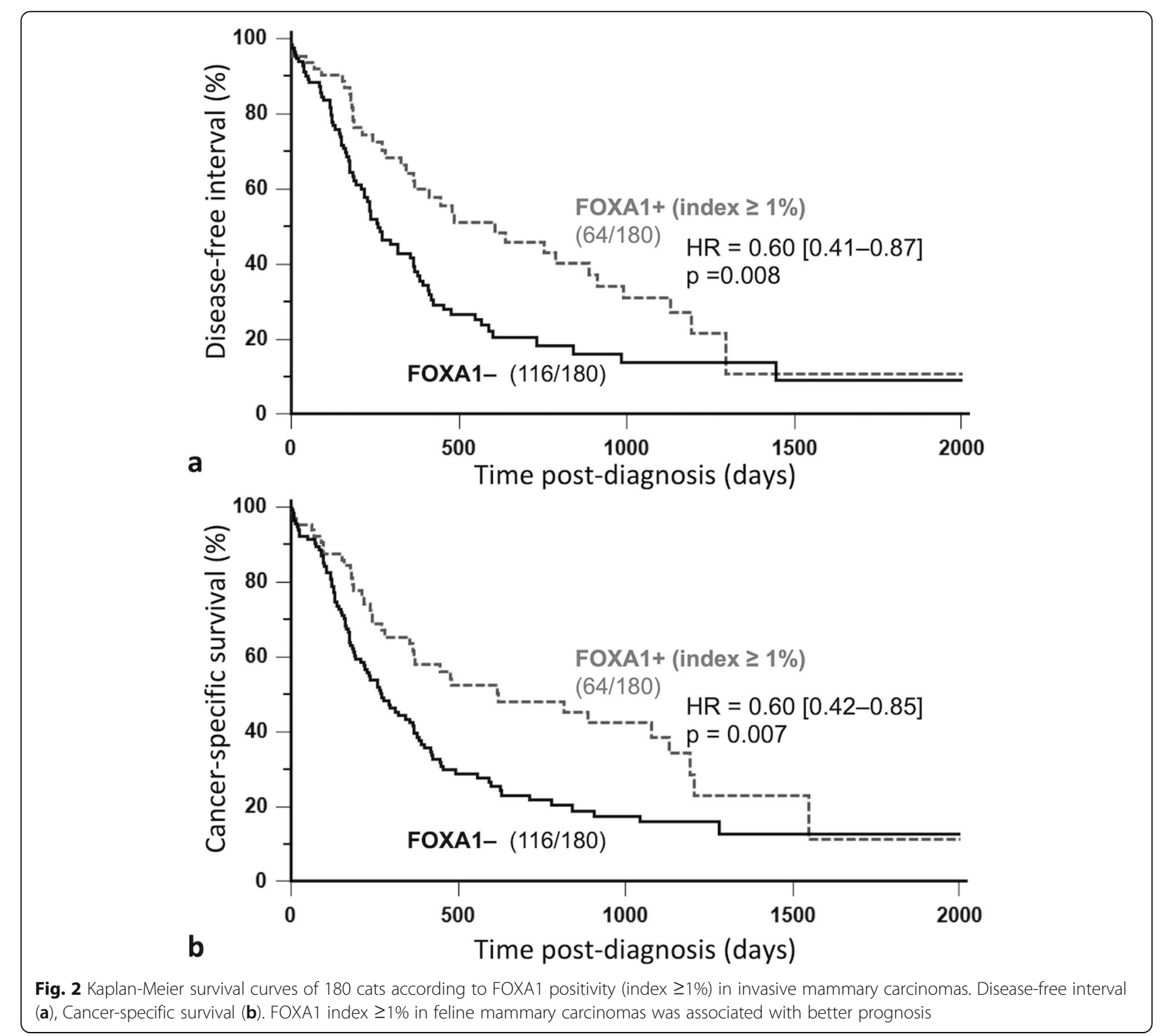

compared to the basal-like AR+FOXA1- CK14+ subgroup that was associated with a worse outcome.

By multivariate survival analysis, the non basal-like AR+ FOXA1+CK14- subgroup was associated with longer cancer-specific survival $(\mathrm{HR}=0.26,95 \% \mathrm{CI}: 0.07-0.89$, $p=0.033) \quad$ compared to the basal-like AR+ FOXA1- CK14+ subgroup $(\mathrm{HR}=1.00)$ independently of the pathologic tumor size ( $\mathrm{pT} \geq 20 \mathrm{~mm}$ : $\mathrm{HR}=2.15,95 \%$ CI: $1.10-4.19, p=0.026)$ and pathologic nodal stage ( $\mathrm{pN}+$ : $\mathrm{HR}=2.28$, 95\% CI: 1.17-4.46, $p=0.017$ ) (Table 5). These results suggest that loss of FOXA1 expression and basal marker CK14 expression in triple-negative FMCs split the $\mathrm{AR}+$ phenotype into two subgroups of different aggressiveness, a good-prognosis non basal-like AR+ FOXA1+ CK14- subgroup, and a poor-prognosis basal-like AR+ FOXA1-CK14+ subgroup.

\section{Discussion}

This study investigates for the first time AR and FOXA1 expressions in a large cohort of feline invasive mammary carcinomas. The first objective was thus to determine if $\mathrm{AR}$ and FOXA1 expressions are common in FMCs. Most of the carcinomas (97\%) contained AR-positive neoplastic cells. At 10\% threshold for AR positivity, 92\% of the cases would be considered positive for AR. In women, the frequency of AR expression in invasive ductal mammary carcinomas varies considerably depending on the studies and the thresholds used [44-51]. At the frequently used 10\% threshold for AR positivity, from 58\% [51] to 90\% [46] of breast cancers are AR+, compared to $92 \%$ in cats with FMCs. Cats tend thus to have a higher AR expression in FMCs than women with breast cancer. 
Table 4 Prognostic value of FOXA1 index $\geq 1 \%$ in FMCs estimated by multivariate analysis (180 cases)

\begin{tabular}{|c|c|c|c|c|}
\hline & Categories & $\mathrm{p}$ & $\mathrm{HR}$ & $95 \% \mathrm{Cl}$ \\
\hline \multicolumn{5}{|l|}{ Disease-free interval } \\
\hline FOXA1 positivity & FOXA $1 \geq 1 \%$ versus $<1 \%$ & 0.009 & 0.58 & $0.39-0.87$ \\
\hline Pathologic tumor size & $\mathrm{pT} \geq 20 \mathrm{~mm}$ versus $<20 \mathrm{~mm}$ & 0.047 & 1.46 & $1.01-2.12$ \\
\hline Distant metastasis & M1 versus M0-MX & $<0.0001$ & 5.05 & $2.41-10.56$ \\
\hline \multicolumn{5}{|l|}{ Overall survival } \\
\hline FOXA1 positivity & FOXA $1 \geq 1 \%$ versus $<1 \%$ & 0.030 & 0.70 & $0.50-0.96$ \\
\hline Pathologic tumor size & $\mathrm{pT} \geq 20 \mathrm{~mm}$ versus $<20 \mathrm{~mm}$ & 0.001 & 1.69 & $1.24-2.30$ \\
\hline Distant metastasis & $\mathrm{M} 1$ versus $\mathrm{M0}-\mathrm{MX}$ & 0.005 & 2.82 & $1.36-5.82$ \\
\hline \multicolumn{5}{|l|}{ Cancer-specific survival } \\
\hline FOXA1 positivity & FOXA $1 \geq 1 \%$ versus $<1 \%$ & 0.032 & 0.65 & $0.44-0.96$ \\
\hline Pathologic tumor size & $\mathrm{pT} \geq 20 \mathrm{~mm}$ versus $<20 \mathrm{~mm}$ & 0.004 & 1.69 & $1.18-2.42$ \\
\hline Pathologic nodal stage & $\mathrm{pN}+$ versus $\mathrm{pNO}-\mathrm{pNX}$ & 0.002 & 1.83 & $1.26-2.66$ \\
\hline Distant metastasis & M1 versus M0-MX & 0.001 & 3.47 & $1.66-7.23$ \\
\hline
\end{tabular}

In our cohort, $43 \%$ of the carcinomas contained FOXA1positive neoplastic cells. At FOXA1 index $\geq 1,36 \%$ of the FMCs were considered positive for FOXA1. The prognostic cutoff for FOXA1 used in breast cancer varies considerably [52-55], reaching $71 \%$ for hormone receptor-positive breast cancers [52]. The frequency of FOXA1 positivity in breast cancer ranges from 41.5 to $85.9 \%$ of cases [52, 5662]. Thus FOXA1 expression in breast cancer seems to be considerably higher than in FMCs. This difference may partly be due to the fact that most of the FMCs are triplenegative carcinomas, whereas FOXA1 is strongly associated with the luminal phenotype in women $[57,59]$.

The second objective of this study was to assess the relationships between AR, FOXA1, and the other clinical and pathological features of feline invasive mammary carcinomas. In the present study, there was a negative correlation between AR overexpression and pathologic tumor size, in agreement with results reported in human breast cancer [50, 51]. For instance, Ogawa et al. (2008) reported that $14 \%(19 / 134)$ of AR-positive breast cancers had a tumor size $>3 \mathrm{~cm}$ compared to $26 \%(21 / 81)$ of ARnegative carcinomas [50]. We also found a negative correlation between AR overexpression and lymphovascular invasion, including in the triple-negative subcohort. However, according to Tsang et al. (2014) in a large cohort of 1144 patients with primary invasive breast cancer, there is no significant correlation between AR positivity and lymphovascular invasion in human breast cancer [63]. We observed a negative correlation between AR expression and pathologic nodal stage, a finding also reported in breast cancer: Ogawa et al. (2008) reported that 73\% (100/ 136) of AR-positive invasive mammary carcinomas were free of regional lymph node metastasis, compared to only $60 \%(49 / 81)$ of AR-negative breast cancers [50]. AR overexpression in FMCs was also negatively associated with the clinical stage at diagnosis, as in human breast cancer: according to Alshenawy et al. (2012), 91\% (98/107) of AR-positive breast cancers were diagnosed at stages III, compared to $58 \%(25 / 43)$ of AR-negative carcinomas [44]. AR expression was negatively associated with the Elston and Ellis histological grades, including in triplenegative FMCs considered separately. This negative association between AR and histological grade has been reported in multiple publications on breast cancers, including in TNBCs alone [28, 64-66]. For example Tang et al. (2012) reported that 70\% (77/111) of AR-negative triple-negative carcinomas were grade III while about $70 \%$ (11/16) of AR-positive triple-negative carcinomas were grade I-II [66]. And finally AR expression was negatively correlated with tumor-associated inflammation visible on HES-stained sections. Interestingly, tumor-associated inflammation was associated with poor prognosis in cats of the present study and in the veterinary literature [67]. A similar finding was recently reported in human breast cancer: according to Gujam et al. (2018), AR expression is associated with reduced tumor-associated inflammation [68]. We can conclude that as in human breast cancer, AR positivity in FMCs is mainly associated with favorable prognostic features: smaller pathologic tumor size, negative nodal stage, lower clinical stage, lower histological grade, absence of lymphovascular invasion, and lower tumor-associated inflammation.

FOXA1 positivity in FMCs was negatively associated with pathologic nodal stage, including in triple-negative FMCs, as reported in human breast cancer [56, 69, 70]. According to Albergaria et al. (2009) 31\% (30/97) of FOXA1-positive breast cancers were $\mathrm{pN}+$ compared to $69 \%$ (67/97) in FOXA1-negative carcinomas. However in 


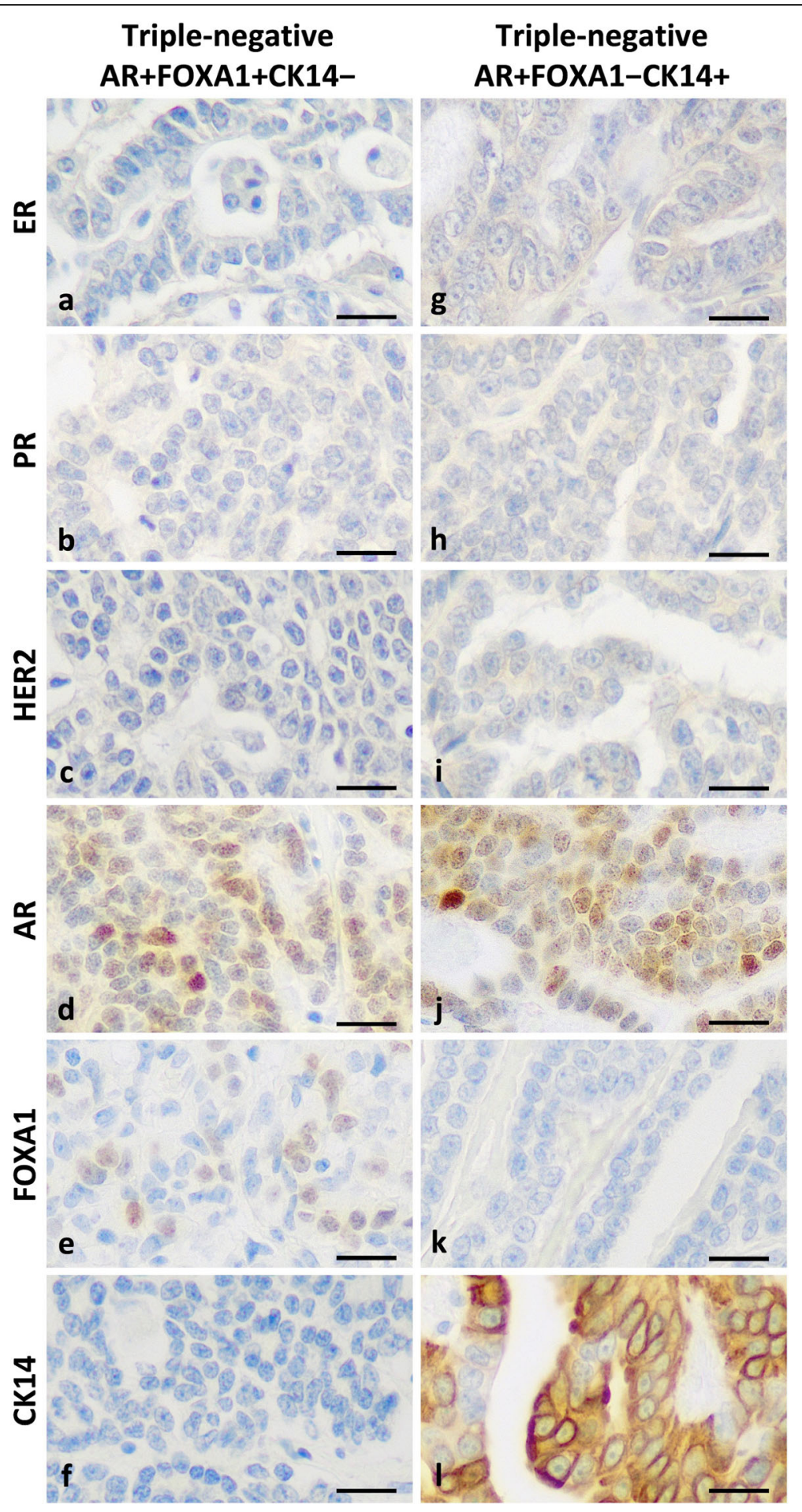

Fig. 3 Diversity of AR-positive triple-negative feline mammary carcinomas. Left panel, non-basal-like AR+ FOXA1+CK14- triple-negative feline invasive mammary carcinomas determined by immunohistochemistry were characterized by: ER negativity (a), PR negativity (b), HER2 negativity (c), AR positivity (d), FOXA1 positivity (e), and CK14 negativity (f). Right panel, basal-like AR+ FOXA1- CK14+ triple-negative feline invasive mammary carcinomas determined by immunohistochemistry were characterized by: ER negativity (g), PR negativity (h), HER2 negativity (i), AR positivity (j), FOXA1 negativity (k), and CK14 positivity (I). Peroxidase-DAB revelation system. Original magnification 400x. Bar $=20 \mu \mathrm{m}$ 

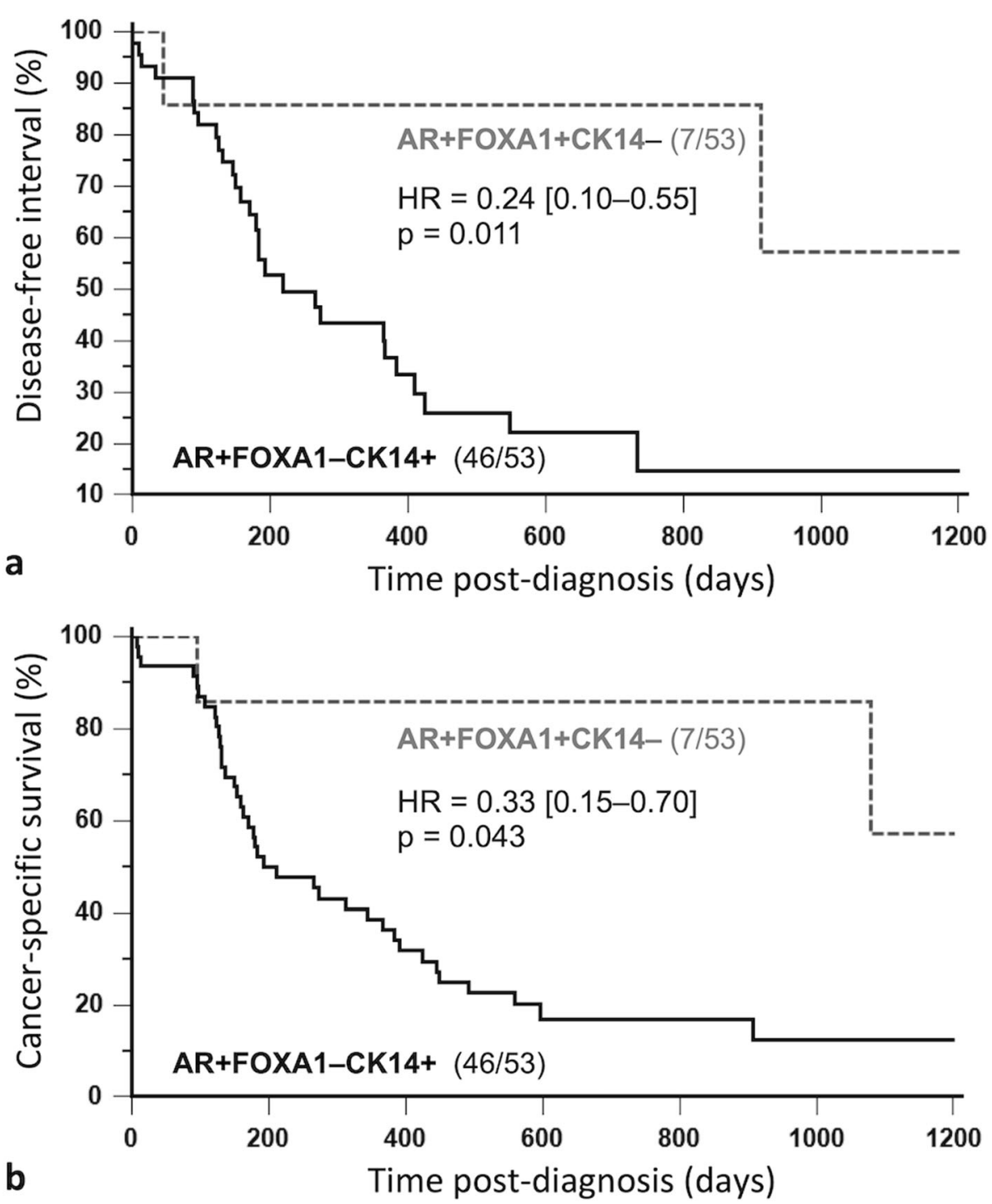

Fig. 4 Kaplan-Meier survival curves of 53 cats with AR+ triple-negative mammary carcinomas according to FOXA1/CK14 status. Disease-free interval (a), Cancer-specific survival (b). Within AR+ triple-negative mammary carcinomas, the FOXA1+CK14- phenotype was associated with much better prognosis than the FOXA1-CK14+ phenotype (i.e., loss of FOXA1 expression and basal-like subtype)

ER-negative breast cancers, no association between FOXA1 and nodal stage was found [56]. FOXA1 was negatively associated with the clinical stage of FMCs, including triple-negative FMCs considered separately. Whereas in human breast cancer, no significant correlations were found between clinical stage and FOXA1 [54]. We also observed a negative correlation between FOXA1 and Elston and Ellis histological grade that was also observed in triple-negative FMCs. In human breast cancer, many studies have reported a negative association between FOXA1 and grade in consecutive series of breast cancers $[56,58$, 71 , but not in ER-negative breast cancers considered separately [56]. FOXA1 index $\geq 1 \%$ was also negatively correlated with lymphovascular invasion, including in triplenegative FMCs, as sometimes reported in breast cancer: Albergaria et al. (2009) found that 37\% (30/81) of FOXA1-

Table 5 Prognostic value of FOXA1 and CK14 association in AR+ triple-negative FMCs (multivariate analysis, 53 cases)

\begin{tabular}{|c|c|c|c|c|}
\hline Cancer-specific survival & Categories & $\mathrm{p}$ & $H R$ & $95 \% \mathrm{Cl}$ \\
\hline AR/FOXA1/CK14 status & AR+ FOXA1+CK14- versus AR+ FOXA1-CK14+ & 0.033 & 0.26 & $0.07-0.89$ \\
\hline Pathologic tumor size & pT $\geq 20 \mathrm{~mm}$ versus $<20 \mathrm{~mm}$ & 0.026 & 2.15 & $1.10-4.19$ \\
\hline Pathologic nodal stage & $\mathrm{pN}+$ versus pNO-pNX & 0.017 & 2.28 & $1.16-4.46$ \\
\hline
\end{tabular}


positive breast cancers were LVI+ compared to $55 \%$ (67/ 122) of FOXA1-negative carcinomas [56]. FOXA1 in our cohort was negatively associated with the Ki-67 proliferation index, in agreement with data reported in human breast cancer [52, 69]. And finally FOXA1 was positively associated with PR, AR and the luminal phenotype. Similarly, in the medical literature, most publications report a very strong correlation between FOXA1 positivity in breast cancers and the expression of the hormone receptors ER and PR [56, 57, 69, 72], confirmed by two meta-analyses $[70,73]$, AR [74], and the luminal-A phenotype [56, 57, 69, 72]. Although the positive correlation between FOXA1 and PR was also observed in our cohort, it is however interesting to note that FOXA1 and ER did not show significant association in cats of our cohort. This suggests a loss of the normal interplay between FOXA1 and ER [26] in feline mammary carcinomas. Loss of FOXA1 expression in $\mathrm{ER}+$ breast cancers has been associated with resistance to endocrine therapy $[69,75,76]$, thus ER+ FOXA1- FMCs in our cohort may not be hormone-responsive mammary carcinomas. Overall, we found that as in human breast cancer, FOXA1 positivity in FMCs was associated with favorable features such as negative nodal stage, lower clinical stage, lower histological grade and lower proliferation index. Most importantly FOXA1 was positively associated with $A R$, including in triple-negative FMCs.

The third objective of this study was to investigate the prognostic significance of AR and FOXA1 in FMCs, in order to evaluate their significance in the feline patient. AR overexpression was associated with longer disease-free interval, overall survival, and cancer-specific survival by univariate and multivariate survival analyses, independently of clinical stage at diagnosis (tumor size, lymph node metastasis, distant metastasis). AR overexpression was associated with favorable outcomes in both luminal and triple-negative FMCs. In human breast cancer also, AR overexpression is associated with better outcomes in patients with luminal [51, 77] and triple-negative carcinomas [66, 77-79]. In this study, FOXA1 index $\geq 1 \%$ was also associated with a longer disease-free interval, overall survival, and cancer-specific survival, by multivariate survival analyses, again with components of clinical stage as covariates of the models (tumor size, nodal status, distant metastasis). This finding was also observed in luminal but not in triple-negative FMCs. The significance of FOXA1 expression appears to be similar in human oncology, as FOXA1 positivity of breast carcinomas is associated with better outcomes especially in luminal carcinomas $[52,59,72,80]$. By multivariate survival analysis, Hisamatsu et al. (2012) reported that FOXA1 was associated with longer relapse-free survival independently of the pathological size, histological grade and ER expression in luminal breast cancers [52]. In TNBC, FOXA1 expression alone was not associated with prognosis. However, Albergaria et al. (2009) reported a near significant result $(p=0.06)$ with the risk of disease progression being higher for FOXA1-negative TNBCs than for FOXA1+ TNBCs [56].

The fourth and last objective of our study was to better characterize AR-positive triple-negative FMCs in order to define a "luminal-AR" subtype. Indeed, gene expression studies have shown that TNBCs in women are a heterogeneous group, comprising a stable luminal-AR subtype, which has been reported by Lehmann et al. [20, 21], Burstein et al. [22], and Jézéquel et al. (referred to as Cluster 1 or $\mathrm{C} 1$ in their study) [23, 24]. Other groups have confirmed that the luminal-AR subtype is a distinct subtype of TNBC, characterized by high expression of the androgen receptor and enrichment in the hormone-regulated pathways that play an important role in steroid synthesis, and androgen/ estrogen metabolism despite the absence of ER [81, 82]. Since transcriptome studies are expensive, Guiu et al. (2015) proposed a definition of the luminal-AR subtype using immunohistochemistry. The simple expression of AR is not enough to define a luminal-AR TNBC because ARpositive triple-negative carcinomas contain multiple subgroups with different behaviors and prognoses. FOXA proteins bind to DNA and induce rearrangements that facilitate DNA binding with other regulators such as steroid hormone receptors. In the healthy mammary epithelial cell, FOXA1 is necessary for the expression of ER $\alpha$ target genes [26]. In addition, preclinical studies suggest that FOXA1 allows AR to bind to ER DNA binding sites and thereby induce transcription of ER-related genes and thereby stimulate tumor proliferation [27]. Guiu et al. (2015) investigated whether AR and FOXA1 coexpression (evaluated by immunohistochemistry) could define the luminal-AR subtype of TNBC. In their study, 25.9\% (126/487) of the triplenegative carcinomas expressed AR and 15.2\% (70/460) were both AR- and FOXA1-positive, called luminal-AR [28]. This frequency was consistent with gene expression studies, in which 11 to $15.4 \%$ of triple-negative carcinomas were luminal-AR [20, 83]. Luminal-AR TNBCs defined by double positivity to AR and FOXA1 according to Guiu et al. were associated with a worse outcome than other TNBCs in terms of recurrence-free and overall survivals [84]. Other authors have used other immunohistochemical definitions of the luminal-AR subtype. For instance, Astvatsaturyan et al. (2018) defined luminal-AR TNBCs by their positivity to $\mathrm{AR}$ and negative expression of Epidermal Growth Factor Receptor (EGFR), a basal marker. In their study the luminal-AR subgroup (AR+EGFR-, 9\% of TNBCs) was associated with a better disease-free survival compared to other TNBCs [29]. In our current study, we decided to combine AR, FOXA1 and the basal marker CK14 in order to better characterize the luminal-AR subgroup of feline mammary carcinomas. And by doing so, we were able to find a non-basal like subgroup characterized by double positivity to AR and FOXA1 (AR+ FOXA1+ CK14-) that might represent the luminal-AR subtype of 
triple-negative FMCs, and a basal-like subgroup with AR positivity but loss of FOXA1 expression (AR+ FOXA1CK14+). The non basal-like AR+ FOXA1+CK14- subgroup (7/53 cases, i.e., $13 \%$ of $\mathrm{AR}+$ triple-negative cases) was associated with a better outcome compared to the basal-like AR+ FOXA1-CK14+ subgroup by univariate and multivariate survival analyses. Inspired from the immunohistochemical definitions of luminal-AR TNBCs (AR+ FOXA1+ according to Guiu et al., AR+ EGFR- according to Astvatsaturyan et al.), we propose that luminal-AR triple-negative mammary carcinomas of cats can be defined by an AR+ FOXA1+ CK14- phenotype.

\section{Conclusion}

In conclusion, we have shown that AR and FOXA1 were mainly associated with favorable features such as lower stage and lower histological grade, but also correlated together, as reported in human breast cancer, despite the fact that AR was more commonly expressed in FMCs than in breast cancers, and conversely FOXA1 was less frequently expressed in cats than in women with invasive mammary carcinomas. Both AR and FOXA1 were strong and favorable prognostic factors, independently of tumor stage at diagnosis. Within AR-positive triple-negative FMCs, we identified a non-basal AR+FOXA1+CK14subgroup with AR and FOXA1 coexpression, which appears similar to the luminal-AR TNBC subgroup described in humans, and is associated with a favorable outcome. Female cats with invasive mammary carcinomas may thus be interesting spontaneous animal models to investigate new cancer therapy strategies such as antiandrogen or anti-androgen receptor molecules, especially in the aggressive and potentially non-hormone-responsive triple-negative basal-like AR+ FOXA1-CK14+ subgroup.

\footnotetext{
Abbreviations

AR: Androgen receptor; CK14: Cytokeratin 14; ER: Estrogen receptor alpha; FMC: Feline invasive mammary carcinoma; FOXA1: Forkhead box protein A1; HER2: Human epidermal growth factor receptor-2; HIER: Heat-induced epitope retrieval; HR: Hazard ratio; LVI: Lymphovascular invasion; pN: Pathologic nodal stage; PR: Progesterone receptor; pT: Pathologic tumor size; TNBC: Triple-negative breast cancer
}

\section{Acknowledgments}

The authors thank Dr. Mélanie Pohu, Dr. Floriane Morio, and Dr. Clotilde de Brito, who helped in collecting the clinical and follow-up data, as well as the veterinary pathologists (Dr. Jean-Loïc Le Net, Dr. Virginie Théau, Dr. Pierre Lagourette, Dr. Olivier Albaric and Dr. Sophie Labrut) who performed the initial diagnoses of feline mammary carcinomas, and the technicians in histopathology (Mr. Bernard Fernandez, Mrs. Florence Lezin, and Mrs. Catherine Guéreaud) who made the slides. We are very grateful to Prof. Dominique Fanuel (DVM) for critical review of this work. Finally, we thank the referring veterinarians and the owners of the cats included in this study, who gave us the clinical and follow-up data.

\section{Authors' contributions}

$\mathrm{FN}, \mathrm{JA}$ and $\mathrm{MC}$ conceived and designed the experiments. DL and $\mathrm{MC}$ ensured that the data collected in cats were analyzed in a comparative oncology approach. ED, JA, DL and FN carried out the histological and immunohistochemical analysis of the mammary carcinomas. VR, PB, ED and
FN analyzed the results. ED and FN drafted the manuscript. All authors read and approved the final manuscript.

\section{Authors' information}

ED, JA and FN (DVM) are ECVP Diplomates (European Veterinary Specialists in Veterinary Pathology). $\mathrm{DL}(\mathrm{MD})$ is a pathologist, $\mathrm{MC}(\mathrm{MD})$ is a medical oncologist, both specialized in breast cancer and glioblastomas. VR and PB (DVM) are small animal veterinary practitioners.

\section{Funding}

This work was supported by the French National Cancer Institute (INCa, Institut National du Cancer) with a grant for translational research (INCaDHOS 2010, Prof. M. Campone); by a grant for PhD students from the Ministry of Education and Higher Education of Lebanon (Dr. Elie Dagher); and by Roche Diagnostics GmbH, Germany, which provided financial and technical support for the immunohistochemical characterization of the carcinomas. The funders had no role in study design, data collection, analysis and interpretation, decision to publish, or preparation of the manuscript.

\section{Availability of data and materials}

The datasets used and analyzed during this study are available from the corresponding author on reasonable request.

\section{Ethics approval and consent to participate}

Owners' written consent to include their pet cats in this retrospective study was obtained prior to inclusion. The local animal welfare committee of Oniris (CERVO, Comité d'Ethique en Recherche clinique et épidémiologique Vétérinaire d'Oniris, Nantes, France) approved the study design before inclusions started.

\section{Consent for publication \\ Not applicable.}

\section{Competing interests}

The authors declare that they have no competing interests.

\section{Author details}

${ }^{1}$ AMaROC, Oniris (Nantes Atlantic College of Veterinary Medicine, Food Science and Engineering), Oniris site Chantrerie, CS40706, 44307, Cedex 3, Nantes, France. ${ }^{2}$ CRCINA, INSERM, Université d'Angers, Université de Nantes, Nantes, France. ${ }^{3}$ Hôtel-Dieu CHU de Nantes, Anatomie Pathologique, cedex 01, 44093 Nantes, France. ${ }^{4}$ Integrated Center for Oncology, ICO, 15 rue André Boquel, cedex 02, 49055 Angers, France.

Received: 19 July 2019 Accepted: 18 December 2019 Published online: 30 December 2019

\section{References}

1. Dorn CR, Taylor DO, Frye FL, Hibbard HH. Survey of animal neoplasms in alameda and contra Costa counties, California. I. Methodology and description of cases. J Natl Cancer Inst. 1968;40:295-305.

2. Brodey R. Canine and feline neoplasia. Adv Vet Sci Comp Med. 1970;14:309-54.

3. Hayden DW, Nielsen SW. Feline mammary tumours. J Small AnimPract. 1971;12:687-98.

4. Castagnaro M, Casalone C, Bozzetta E, De Maria R, Biolatti B, Caramelli M. Tumour grading and the one-year post-surgical prognosis in feline mammary carcinomas. J Comp Pathol. 1998;1 19:263-75.

5. Castagnaro M, Casalone C, Ru G, Nervi GC, Bozzetta E, Caramelli M. Argyrophilic nucleolar organiser regions (AgNORs) count as indicator of post-surgical prognosis in feline mammary carcinomas. Res Vet Sci. 1998;64:97-100.

6. Castagnaro M, De Maria R, Bozzetta E, Ru G, Casalone C, Biolatti B, et al. Ki67 index as indicator of the post-surgical prognosis in feline mammary carcinomas. Res Vet Sci. 1998;65:223-6.

7. Ito T, Kadosawa T, Mochizuki M, Matsunaga S, Nishimura R, Sasaki N. Prognosis of malignant mammary tumor in 53 cats. J Vet Med Sci. 1996;58:723-6.

8. Millanta F, Calandrella M, Citi S, Della Santa D, Poli A. Overexpression of HER-2 in feline invasive mammary carcinomas: an immunohistochemical survey and evaluation of its prognostic potential. Vet Pathol. 2005:42:30-4.

9. Seixas F, Palmeira C, Pires MA, Bento MJ, Lopes C. Grade is an independent prognostic factor for feline mammary carcinomas: a clinicopathological and survival analysis. Vet J. 2011;187:65-71. 
10. Brunetti B, Asproni P, Beha G, Muscatello LV, Millanta F, Poli A, et al. Molecular phenotype in mammary tumours of queens: correlation between primary tumour and lymph node metastasis. J Comp Pathol. 2013;148:206-13.

11. Burrai GP, Mohammed SI, Miller MA, Marras V, Pirino S, Addis MF, et al. Spontaneous feline mammary intraepithelial lesions as a model for human estrogen receptor- and progesterone receptor negative breast lesions. BMC Cancer. 2010;10:156.

12. Caliari D, Zappulli V, Rasotto R, Cardazzo B, Frassineti F, Goldschmidt MH, et al. Triple-negative vimentin-positive heterogeneous feline mammary carcinomas as a potential comparative model for breast cancer. BMC Vet Res. 2014;10:185.

13. Dagher E, Abadie J, Loussouarn D, Fanuel D, Campone M, Nguyen F. BCl-2 expression and prognostic significance in feline invasive mammary carcinomas: a retrospective observational study. BMC Vet Res. 2019;15:25.

14. De Maria R, Olivero M, lussich S, Nakaichi M, Murata T, Biolatti B, et al. Spontaneous feline mammary carcinoma is a model of HER2 overexpressing poor prognosis human breast cancer. Cancer Res. 2005;65:907-12.

15. Millanta F, Calandrella M, Vannozzi I, Poli A. Steroid hormone receptors in normal, dysplastic and neoplastic feline mammary tissues and their prognostic significance. Vet Rec. 2006;158:821-4.

16. Rasotto R, Caliari D, Castagnaro M, Zanetti R, Zappulli V. An immunohistochemical study of HER-2 expression in feline mammary tumours. J Comp Pathol. 2011;144:170-9.

17. Soares M, Correia J, Rodrigues P, Simões M, De Matos A, Ferreira F. Feline HER2 protein expression levels and gene status in feline mammary carcinoma: optimization of immunohistochemistry $(\mathrm{IHC})$ and in situ hybridization (ISH) techniques. Microsc Microanal. 2013;19:876-82.

18. Soares M, Correia J, Peleteiro MC, Ferreira F. St Gallen molecular subtypes in feline mammary carcinoma and paired metastases-disease progression and clinical implications from a 3-year follow-up study. Tumour Biol. 2016;37:4053-64.

19. Wiese DA, Thaiwong T, Yuzbasiyan-Gurkan V, Kiupel M. Feline mammary basal-like adenocarcinomas: a potential model for human triple-negative breast cancer (TNBC) with basal-like subtype. BMC Cancer. 2013;13:403.

20. Lehmann BD, Bauer JA, Chen X, Sanders ME, Chakravarthy AB, Shyr Y, et al. Identification of human triple-negative breast cancer subtypes and preclinical models for selection of targeted therapies. J Clin Invest. 2011;121:2750-67.

21. Lehmann BD, Jovanović B, Chen X, Estrada MV, Johnson KN, Shyr Y, et al. Refinement of triple-negative breast Cancer molecular subtypes: implications for Neoadjuvant chemotherapy selection. PLoS One. 2016;11:e0157368.

22. Burstein MD, Tsimelzon A, Poage GM, Covington KR, Contreras A, Fuqua SA, et al. Comprehensive genomic analysis identifies novel subtypes and targets of triple-negative breast cancer. Clin Cancer Res. 2015;21:1688-98.

23. Jézéquel $P$, Loussouarn $D$, Guérin-Charbonnel C, Campion L, Vanier A, Gouraud W, et al. Gene-expression molecular subtyping of triple-negative breast cancer tumours: importance of immune response. Breast Cancer Res. 2015;17:43.

24. Jézéquel P, Kerdraon O, Hondermarck H, Guérin-Charbonnel C, Lasla H, Gouraud W, et al. Identification of three subtypes of triple-negative breast cancer with potential therapeutic implications. Breast Cancer Res. 2019;21:65

25. Katoh M, Igarashi M, Fukuda $H$, Nakagama $H$, Katoh M. Cancer genetics and genomics of human FOX family genes. Cancer Lett. 2013;328:198-206.

26. Carroll JS, Liu XS, Brodsky AS, Li W, Meyer CA, Szary AJ, et al. Chromosomewide mapping of estrogen receptor binding reveals long-range regulation requiring the forkhead protein FoxA1. Cell. 2005;122:33-43.

27. Robinson JL, Macarthur S, Ross-Innes CS, Tilley WD, Neal DE, Mills IG, et al. Androgen receptor driven transcription in molecular apocrine breast cancer is mediated by FoxA1. EMBO J. 2011;30:3019-27.

28. Guiu S, Charon-Barra C, Vernerey D, Fumoleau P, Campone M, Spielmann M, et al. Coexpression of androgen receptor and FOXA1 in nonmetastatic triple-negative breast cancer: ancillary study from PACS08 trial. Future Oncol. 2015;11:2283-97.

29. Astvatsaturyan $\mathrm{K}$, Yue $\mathrm{Y}$, Walts $\mathrm{AE}$, Bose $\mathrm{S}$. Androgen receptor positive triple negative breast cancer: Clinicopathologic, prognostic, and predictive features. PLoS One. 2018;13:e0197827.

30. Moriya T, Kanomata N, Kozuka Y, Fukumoto M, Iwachido N, Hata S, et al Usefulness of immunohistochemistry for differential diagnosis between benign and malignant breast lesions. Breast Cancer. 2009;16:173-8.

31. Shamloula MM, El-Shorbagy SH, Saied EM. P63 and cytokeratin8/18 expression in breast, atypical ductal hyperplasia, ductal carcinoma in situ and invasive duct carcinoma. J Egypt Natl Canc Inst. 2007;19:202-10.

32. Chocteau F, Boulay MM, Besnard F, Valeau G, Loussouarn D, Nguyen F. Proposal for a Histological Staging System of Mammary Carcinomas in Dogs and Cats. Part 2: Feline Mammary Carcinomas. Front Vet Sci. 2019;6:387.
33. Dagher E, Abadie J, Loussouarn D, Campone M, Nguyen F. Feline Invasive Mammary Carcinomas: Prognostic Value of Histological Grading. Vet Pathol. 2019;56(5):660-70

34. Elston CW, Ellis IO. Pathological prognostic factors in breast cancer: I. the value of histological grade in breast cancer: experience from a large study with long-term follow-up. Histopathol. 1991;19:403-10.

35. Morris J. Mammary tumors in the cat: size matters, so early intervention saves lives. J Feline Med Surg. 2013;15:391-400.

36. Owen LN. World Health Organization. Veterinary public health unit \& WHO collaborating Center for Comparative Oncology. 1980. TNM classification of Tumours in domestic animals/ edited by L.N. Owen Geneva: World Health Organization. http:/apps.who.int/iris/handle/10665/68618. Accessed 5 July 2019.

37. Peñafiel-Verdu C, Buendia AJ, Navarro JA, Ramirez GA, Vilafranca M, Altimira $J$, et al. Reduced expression of E-cadherin and $\beta$-catenin and high expression of basal cytokeratins in feline mammary carcinomas with regional metastasis. Vet Pathol. 2012;49:979-87.

38. Gama A, Alves A, Schmitt F. Identification of molecular phenotypes in canine mammary carcinomas with clinical implications: application of the human classification. Virchows Arch. 2008;453:123-32.

39. Guil-Luna S, Sánchez-Céspedes R, Millán Y, De Andrés FJ, Rollón E, Domingo $V$, et al. Aglepristone decreases proliferation in progesterone receptorpositive canine mammary carcinomas. J Vet Intern Med. 2011;25:518-23.

40. Nguyen F, Peña L, Ibisch C, Loussouarn D, Gama A, Rieder N, et al. Canine invasive mammary carcinomas as models of human breast cancer. Part 1: natural history and prognostic factors. Breast Cancer Res Treat. 2018;167:635-48.

41. Yi M, Huo L, Koenig KB, Mittendorf EA, Meric-Bernstam F, Kuerer HM, et al. Which threshold for ER positivity? A retrospective study based on 9639 patients. Ann Oncol. 2014;25:1004-11.

42. Ono M, Tsuda H, Yunokawa M, Yonemori K, Shimizu C, Tamura K, et al. Prognostic impact of Ki-67 labeling indices with 3 different cutoff values, histological grade, and nuclear grade in hormone-receptor-positive, HER2negative, node-negative invasive breast cancers. Breast Cancer. 2015;22:141-52.

43. Wolff AC, Hammond ME, Hicks DG, Dowsett M, McShane LM, Allison KH, et al. Recommendations for human epidermal growth factor receptor 2 testing in breast cancer: American Society of Clinical Oncology/College of American Pathologists clinical practice guideline update. J Clin Oncol. 2013; 31:3997-4013.

44. Alshenawy HA. Prevalence of androgen receptors in invasive breast carcinoma and its relation with estrogen receptor, progesterone receptor and Her2/neu expression. J Egypt Natl Canc Inst. 2012;24:77-83.

45. Elebro K, Borgquist S, Simonsson M, Markkula A, Jirström K, Ingvar C, et al. Combined androgen and estrogen receptor status in breast Cancer: treatment prediction and prognosis in a population-based prospective cohort. Clin Cancer Res. 2015;21:3640-50.

46. Elebro K, Butt S, Dorkhan M, Jernström H, Borgquist S. Age at first childbirth and oral contraceptive use are associated with risk of androgen receptornegative breast cancer: the Malmö diet and Cancer cohort. Cancer Causes Control. 2014;25:945-57.

47. Gonzalez LO, Corte MD, Vazquez J, Junquera S, Sanchez R, Alvarez AC, et al. Androgen receptor expression in breast cancer: relationship with clinicopathological characteristics of the tumors, prognosis, and expression of metalloproteases and their inhibitors. BMC Cancer. 2008;8:149.

48. Hu R, Dawood S, Holmes MD, Collins LC, Schnitt SJ, Cole K, et al. Androgen receptor expression and breast cancer survival in postmenopausal women. Clin Cancer Res. 2011;17:1867-74.

49. Niemeier LA, Dabbs DJ, Beriwal S, Striebel JM, Bhargava R. Androgen receptor in breast cancer: expression in estrogen receptor-positive tumors and in estrogen receptor-negative tumors with apocrine differentiation. Mod Pathol. 2010;23:205-12.

50. Ogawa Y, Hai E, Matsumoto K, Ikeda K, Tokunaga S, Nagahara H, et al. Androgen receptor expression in breast cancer: relationship with clinicopathological factors and biomarkers. Int J Clin Oncol. 2008;13:431-5.

51. Park S, Koo JS, Kim MS, Park HS, Lee JS, Lee JS, et al. Androgen receptor expression is significantly associated with better outcomes in estrogen receptor-positive breast cancers. Ann Oncol. 2011;22:1755-62.

52. Hisamatsu Y, Tokunaga E, Yamashita N, Akiyoshi S, Okada S, Nakashima Y, et al. Impact of FOXA1 expression on the prognosis of patients with hormone receptor-positive breast cancer. Ann Surg Oncol. 2012;19:1145-52.

53. Kawase M, Toyama T, Takahashi S, Sato S, Yoshimoto N, Endo Y, et al. FOXA1 expression after neoadjuvant chemotherapy is a prognostic marker in estrogen receptor-positive breast cancer. Breast Cancer. 2015;22:308-16. 
54. Sasahara M, Matsui A, Ichimura Y, Hirakata Y, Murata Y, Marui E. Overexpression of androgen receptor and Forkhead-box A1 protein in apocrine breast carcinoma. Anticancer Res. 2014;34:1261-7.

55. Tominaga N, Naoi Y, Shimazu K, Nakayama T, Maruyama N, Shimomura A, et al. Clinicopathological analysis of GATA3-positive breast cancers with special reference to response to neoadjuvant chemotherapy. Ann Oncol. 2012;23:3051-7.

56. Albergaria A, Paredes J, Sousa B, Milanezi F, Carneiro V, Bastos J, et al. Expression of FOXA1 and GATA-3 in breast cancer: the prognostic significance in hormone receptor-negative tumours. Breast Cancer Res. 2009;11:R40.

57. Badve S, Turbin D, Thorat MA, Morimiya A, Nielsen TO, Perou CM, et al. FOXA1 expression in breast cancer--correlation with luminal subtype a and survival. Clin Cancer Res. 2007;13:4415-21.

58. Habashy HO, Powe DG, Rakha EA, Ball G, Paish C, Gee J, et al. Forkhead-box A1 (FOXA1) expression in breast cancer and its prognostic significance. Eur J Cancer. 2008:44:1541-51.

59. Hisamatsu Y, Tokunaga E, Yamashita N, Akiyoshi S, Okada S, Nakashima Y, et al. Impact of GATA-3 and FOXA1 expression in patients with hormone receptor-positive/HER2-negative breast cancer. Breast Cancer. 2015;22:520-8.

60. Horimoto Y, Arakawa A, Harada-Shoji N, Sonoue H, Yoshida Y, Himuro T, et al. Low FOXA1 expression predicts good response to neo-adjuvant chemotherapy resulting in good outcomes for luminal HER2-negative breast cancer cases. Br J Cancer. 2015;112:345-51.

61. Hosoda M, Yamamoto M, Nakano K, Hatanaka KC, Takakuwa E, Hatanaka Y, et al. Differential expression of progesterone receptor, FOXA1, GATA3, and p53 between pre- and postmenopausal women with estrogen receptorpositive breast cancer. Breast Cancer Res Treat. 2014;144:249-61.

62. Hu Q, Luo Z, Xu T, Zhang JY, Zhu Y, Chen WX, et al. FOXA1: a promising prognostic marker in breast cancer. Asian Pac J Cancer Prev. 2014;15:11-6.

63. Tsang JY, Ni YB, Chan SK, Shao MM, Law BK, Tan PH, et al. Androgen receptor expression shows distinctive significance in ER positive and negative breast cancers. Ann Surg Oncol. 2014;21:2218-28.

64. Mrklić I, Pogorelić Z, Capkun V, Tomić S. Expression of androgen receptors in triple negative breast carcinomas. Acta Histochem. 2013;115:344-8.

65. Rakha EA, El-Sayed ME, Green AR, Lee AH, Robertson JF, Ellis IO. Prognostic markers in triple-negative breast cancer. Cancer. 2007;109:25-32.

66. Tang D, Xu S, Zhang Q, Zhao W. The expression and clinical significance of the androgen receptor and E-cadherin in triple-negative breast cancer. Med Oncol. 2012;29:526-33.

67. Weijer K, Hart AA. Prognostic factors in feline mammary carcinoma. J Natl Cancer Inst. 1983:70:709-16.

68. Gujam F, Dickson K, McCall P, McMillan D, Edwards J. The relationship between androgen receptor. Components Tumour Microenvironment Surviv Breast Cancer Mol Subtypes Canc Ther Oncol Int J. 2018;11:555814.

69. Mehta RJ, Jain RK, Leung S, Choo J, Nielsen T, Huntsman D, et al. FOXA1 is an independent prognostic marker for ER-positive breast cancer. Breast Cancer Res Treat. 2012;131:881-90.

70. Shou J, Lai Y, Xu J, Huang J. Prognostic value of FOXA1 in breast cancer: a systematic review and meta-analysis. Breast. 2016;27:35-43.

71. Wolf I, Bose S, Williamson EA, Miller CW, Karlan BY, Koeffler HP. FOXA1: growth inhibitor and a favorable prognostic factor in human breast cancer. Int J Cancer. 2007;120:1013-22

72. Thorat MA, Marchio C, Morimiya A, Savage K, Nakshatri H, Reis-Filho JS, et al. Forkhead box A1 expression in breast cancer is associated with luminal subtype and good prognosis. J Clin Pathol. 2008;61:327-32.

73. He K, Zeng H, Xu X, Li A, Cai Q, Long X. Clinicopathological significance of forkhead box protein $A 1$ in breast cancer: a meta-analysis. Exp Ther Med. 2016;11:2525-30.

74. Rangel N, Fortunati N, Osella-Abate S, Annaratone L, Isella C, Catalano MG, et al. FOXA1 and AR in invasive breast cancer: new findings on their coexpression and impact on prognosis in ER-positive patients. BMC Cancer. 2018;18:703.

75. Pratt MA. Paradoxical roles for FOXA1 in anti-estrogen resistance and as a luminal differentiation factor in breast cancer. Gland Surg. 2012;1:9-11.

76. Robinson JL, Carroll JS. FoxA1 is a key mediator of hormonal response in breast and prostate cancer. Front Endocrinol (Lausanne). 2012;3:68.

77. Yu Q, Niu Y, Liu N, Zhang JZ, Liu TJ, Zhang RJ, et al. Expression of androgen receptor in breast cancer and its significance as a prognostic factor. Ann Oncol. 2011;22:1288-94.

78. He J, Peng R, Yuan Z, Wang S, Peng J, Lin G, et al. Prognostic value of androgen receptor expression in operable triple-negative breast cancer: a retrospective analysis based on a tissue microarray. Med Oncol. 2012;29:406-10.
79. Maeda T, Nakanishi Y, Hirotani Y, Fuchinoue F, Enomoto K, Sakurai K, et al. Immunohistochemical co-expression status of cytokeratin 5/6, androgen receptor, and p53 as prognostic factors of adjuvant chemotherapy for triple negative breast cancer. Med Mol Morphol. 2016;49:11-21.

80. Liu N, Niu Y, Wang SL, Yu Q, Zhang RJ, Liu TJ. [Diagnostic and prognostic significance of FOXA1 expression in molecular subtypes of breast invasive ductal carcinomas]. [article in Chinese]. Zhonghua Yi Xue Za Zhi. 2010;90:1403-7.

81. Prat A, Adamo B, Cheang MC, Anders CK, Carey LA, Perou CM. Molecular characterization of basal-like and non-basal-like triple-negative breast cancer. Oncologist. 2013;18:123-33.

82. Yu KD, Zhu R, Zhan M, Rodriguez AA, Yang W, Wong S, et al. Identification of prognosis-relevant subgroups in patients with chemoresistant triplenegative breast cancer. Clin Cancer Res. 2013;19:2723-33.

83. Masuda H, Baggerly KA, Wang Y, Zhang Y, Gonzalez-Angulo AM, Meric-Bernstam $F$, et al. Differential response to neoadjuvant chemotherapy among 7 triplenegative breast cancer molecular subtypes. Clin Cancer Res. 2013;19:5533-40.

84. Guiu S, Mollevi C, Charon-Barra C, Boissière F, Crapez E, Chartron E, et al. Prognostic value of androgen receptor and FOXA1 co-expression in nonmetastatic triple negative breast cancer and correlation with other biomarkers. Br J Cancer. 2018;119:76-9.

\section{Publisher's Note}

Springer Nature remains neutral with regard to jurisdictional claims in published maps and institutional affiliations.
Ready to submit your research? Choose BMC and benefit from:

- fast, convenient online submission

- thorough peer review by experienced researchers in your field

- rapid publication on acceptance

- support for research data, including large and complex data types

- gold Open Access which fosters wider collaboration and increased citations

- maximum visibility for your research: over $100 \mathrm{M}$ website views per year

At BMC, research is always in progress.

Learn more biomedcentral.com/submissions 